\title{
Overweight/obesity in adolescents with type 1 diabetes belonging to an admixed population. A Brazilian multicenter study
}

\author{
Marilia Brito Gomes ${ }^{1}$, Deborah Conte ${ }^{1}$, Karla Rezende Guerra Drummond ${ }^{2}$, Felipe Mallmann³, \\ André Araújo Pinheiro ${ }^{4}$, Franz Schubert Lopes Leal ${ }^{5}$, Paulo Henrique Morales ${ }^{2}$ and Carlos Antonio Negrato ${ }^{6 *}$ (D)
}

\begin{abstract}
Background: To determine the prevalence of overweight/obesity and associated risk factors in Brazilian adolescents with type 1 diabetes (T1D) and its association with diabetic retinopathy (DR) and chronic kidney disease (CKD).

Methods: This study was performed in 14 Brazilian public clinics in ten cities, with 1,760 patients. 367 were adolescents (20.9\%):184 females (50.1\%), 176 (48.0\%) Caucasians, aged $16.4 \pm 1.9$ years, age at diagnosis $8.9 \pm 4.3$ years, diabetes duration $8.1 \pm 4.3$ years, school attendance $10.9 \pm 2.5$ years and $\mathrm{HbA1c} 9.6 \pm 2.4 \%$.

Results: 95 (25.9\%) patients presented overweight/obesity, mostly females. These patients were older, had longer diabetes duration, higher levels of total and LDL-cholesterol, higher prevalence of family history of hypertension, hypertension, undesirable levels of LDL-cholesterol, and metabolic syndrome compared to eutrophic patients. No difference was found regarding ethnicity, $\mathrm{HbA} 1 \mathrm{c}$, uric acid, laboratorial markers of non-alcoholic fatty liver disease (alanine aminotransferase, aspartate aminotransferase, gamma-glutamyl transferase).

Conclusions: Almost one quarter of our patients presented overweight/obesity. These patients had higher prevalence of traditional risk factors for micro and macrovascular diabetes-related chronic complications such as diabetes duration, hypertension, high levels of LDL-cholesterol and metabolic syndrome. The majority of the patients with or without overweight/obesity presented inadequate glycemic control which is also an important risk factor for micro and macrovascular diabetes-related chronic complications. No association was found between overweight/obesity with diabetic CKD, DR and laboratorial markers of non-alcoholic fatty liver disease. The above-mentioned data point out that further prospective studies are urgently needed to establish the clinical prognosis of these young patients.
\end{abstract}

Keywords: Type 1 diabetes, Adolescents, Overweight, Obesity, Diabetes-related chronic complications, Glycemic control, Cardiovascular risk factors

\section{Background}

Type 1 diabetes (T1D) is a common endocrine disorder found in adolescents worldwide, caused by an autoimmune destruction of pancreatic beta-cells [1]. For a long time, T1D was associated with a lean phenotype [1] but

\footnotetext{
*Correspondence: carlosnegrato@uol.com.br

${ }^{6}$ Medical Doctor Program, University of São Paulo- School of Dentistry, Rua Saint Martin 27-07, Bauru, São Paulo Zip Code: 17012433, Brazil

Full list of author information is available at the end of the article
}

in the last decades, obesity has been present among these patients even at diagnosis [2]; however, it can also appear after the initiation of insulin treatment that can contribute to weight gain and clinical characteristics of insulin resistance [3]

Patients with T1D that present obesity and other clinical features of insulin resistance at diagnosis or those who gain weight during treatment are termed as having double-diabetes [4-6]. In general patients with original author(s) and the source, provide a link to the Creative Commons licence, and indicate if changes were made. The images or other third party material in this article are included in the article's Creative Commons licence, unless indicated otherwise in a credit line to the material. If material is not included in the article's Creative Commons licence and your intended use is not permitted by statutory regulation or exceeds the permitted use, you will need to obtain permission directly from the copyright holder. To view a copy of this licence, visit http://creativecommons.org/licenses/by/4.0/. The Creative Commons Public Domain Dedication waiver (http://creativeco mmons.org/publicdomain/zero/1.0/) applies to the data made available in this article, unless otherwise stated in a credit line to the data. 
overweight/obesity show other components of insulin resistance or metabolic syndrome (MS) that are risk factors for the presence of diabetes-related chronic complications (DRCC) [7-9]. A recent meta-analysis has found that approximately one quarter $(23.7 \%)$ of patients with T1D were affected by MS [10]. The presence of MS or insulin resistance are considered as risk factors for the presence of poor glycemic control, CKD and cardiovascular diseases (CVD) [7] and retinopathy [9]. Recently, MS was also associated with the presence non-alcoholic fatty liver disease (NAFDL) in patients with T1D as has recently been demonstrated in a study carried out in a tertiary care center in our country [8]. In this study, patients with altered hepatic images on ultrasound or transient elastography had higher body mass index (BMI) and presence of MS [8].

Some studies have found an association between weight gain and intensive insulin therapy even in those using insulin pumps $[6,11,12]$. Subgroup analyses of the Diabetes Control and Complications Trial (DCCT) and the Epidemiology of Diabetes Interventions and Complications (EDIC) have found that patients who gained weight during the trial presented features associated with increased cardiovascular risk and those in the highest quartile for weight gain exhibited higher blood pressure and a more atherogenic lipid profile [6]. In the same study, those patients in the intensive insulin therapy gained twice as much weight compared to those under conventional care [11]. Greater weight gain was associated with poorer glycemic control at baseline, greater decrease in HbA1c levels, presence of severe hypoglycemic episodes but had no relationship with caloric intake and with physical activity intensity. It is supposed that a decrease in glycosuria and consequent better calorie utilization or even other unknown mechanisms are involved in this process $[11,13]$.

This study aims primarily to investigate the prevalence of overweight and/or obesity and its associated cardiovascular risk factors in Brazilian adolescents with T1D and secondly its association with DRCC.

\section{Methods}

\section{Study design and data collection}

This study had a cross-sectional design and was conducted in 10 Brazilian cities, from all geographic regions of the country, with patients followed in 14 public clinics between 2011/2014.

All patients received free health care $\mathrm{NPH}$ and regular insulins, syringes, needles, glucometers and strips for blood glucose monitoring) from the Brazilian National Health Care System (BNHCS) Each clinic provided data for at least 50 T1D outpatients that were treated by an endocrinologist in secondary or tertiary care settings.
Included patients were those with the diagnosis of T1D done by a physician, the need for continuous insulin use since the diagnosis, at least 13 years of age, and followed at each diabetes center for at least 6 months. Pregnant or lactating women, patients who had an acute infection or ketoacidosis in the three preceding months or had a history of renal transplantation were excluded [14].

The total sample was composed of 1760 patients. They were diagnosed as having T1D between 1960 and 2014. 367 patients $(20.9 \%)$ were adolescents, according to the World Health Organization criteria [15] (10 to 19 years old) and formed the sample of this study. Each center had a local ethics committee that approved the study. Patients and/or their parents where necessary, signed a written informed consent agreeing with the participation in the study.

The collected data were: current age, age at diagnosis, self-reported color-race (White, Black, Brown ("parda"), Asian ("amarela") and Indigenous ("indígena")) [16], diabetes duration, years of school attendance, frequency of self-monitoring of blood glucose (SMBG), smoking status, type of prescribed insulin therapeutic regimens (ITR), self-reported adherence to diet (following at least $80 \%$ of the time the prescribed diet) [17] and to prescribed ITRs [14], BMI and self-reported frequency of physical activity (at least three times a week). Family history of diabetes, obesity, hypertension and coronary diseases in first degree relatives were also assessed. The coexistence of another health care insurance, besides that offered by the BNHCS was also assessed.

Adequate glycemic control was defined as the presence of HbA1c levels $<7.5 \%$ (58 $\mathrm{mmol} / \mathrm{mol})$ [18], and inadequate glycemic control was defined as HbA1c levels $\geq 7.5 \%$ ( $58 \mathrm{mmol} / \mathrm{mol})$. HbAlc was measured using high-performance liquid chromatography HPLC (BioRad Laboratories, Hercules, California, USA). The last value of $\mathrm{HbA} 1 \mathrm{c}$ in the previous year was obtained from the medical records. Fasting triglycerides, HDL cholesterol, total cholesterol and laboratorial markers of NAFLD such as alanine aminotransferase (ALT), aspartate aminotransferase (AST) and gamma-glutamyl transferase, were measured using enzymatic techniques and serum uric acid by an uricase-based commercial (mg/dl). Creatinine was measured using a colorimetric assay kit, corrected for standardized creatinine assay by mass spectrometry. All the above measurements were performed with BioSystem (model A25; Barcelona, Spain). Friedewald's equation was used to calculate LDL cholesterol values [19]. ITRs were stratified as follows: exclusive use of intermediate insulin (NPH) or regular insulin, longacting insulin analogs plus short acting insulin or the use of continuous subcutaneous insulin infusion (CSII). Normal weight was defined as a BMI of percentile $\geq 3$ 
and $\leq 85$, underweight as a BMI of percentile $<3$, overweight as a BMI of $>85$ th percentile, and obesity as a BMI of $>97$ th percentile according to age and gender [20] and current smoking as the use of more than one cigarette per day. Elevated blood pressure and hypertension for adolescents were defined according to age, sex and height. Elevated blood pressure was considered as blood pressure values $\geq 90$ th percentile to $<95$ th percentile or $120 / 80 \mathrm{~mm} \mathrm{Hg}$ to $<95$ th percentile for children aged 10 to $<13$ years, and $120 /<80$ to $129 /<80 \mathrm{~mm} \mathrm{Hg}$ for those $\geq 13$ years old [21]. Hypertension was defined as systolic blood pressure and/or diastolic blood pressure $\geq 95^{\text {th }}$ percentile or $130 / 80$ to $139 / 89 \mathrm{~mm} \mathrm{Hg}$ for children aged 10 to $<13$ years and $\geq 130 / 80$ for those with $\geq 13$ years old $[18,21]$. Undesirable levels of LDLCholesterol were considered as $\geq 100 \mathrm{mg} / \mathrm{dl}$ [18].

\section{Sample calculation and economic status evaluation}

Sample calculation of the study has been previously described $[14,22]$. The sample represented the distribution of T1D cases across four geographic regions of Brazil, estimated using the overall population distribution reported in the 2000 Brazilian Institute of Geography and Statistics (IBGE) Population Census [23], combined with national estimates of diabetes prevalence, to determine the minimum number of patients to be studied in each region [24]. Economic status was defined according to the Brazilian Economic Classification Criteria that takes in account the education level [25]. The following economic status categories were considered: high, middle, low, and very low.

\section{Diabetes-related chronic complications assessment Evaluation of renal function}

Renal function was estimated by the CKD-EPI equation [26] in patients with age $\geq 16$ years, by the Schwartz formula in patients younger than 16 years [27] and was expressed as estimated glomerular filtration rate (eGFR) in milliliters per minute per $1.73 \mathrm{~m}^{2}\left(\mathrm{~mL} / \mathrm{min} / 1.73 \mathrm{~m}^{2}\right)$. Albuminuria concentration (immunoturbidimetry, detection limit: $0.01 \mathrm{mg} / \mathrm{dl}$ ) was measured at least twice from a morning urine sample. The presence of albuminuria was defined as an albuminuria $\geq 30 \mathrm{mg} / \mathrm{dl}$. Patients with normal renal function had an eGFR $\geq 60 \mathrm{~mL} / \mathrm{min} / 1.73 \mathrm{~m}^{2}$ and the absence of albuminuria. CKD was defined as an eGFR $<60 \mathrm{~mL} / \mathrm{min} / 1.73 \mathrm{~m}^{2}$, with or without the presence of albuminuria or an eGFR $\geq 60 \mathrm{~mL} / \mathrm{min} / 1.73 \mathrm{~m}^{2}$ with the presence of albuminuria $[28,29]$.

\section{Evaluation of retinopathy}

The screening for diabetic retinopathy (DR) was performed by mydriatic binocular indirect ophthalmoscopy (BIO), EyeTec (OBI OSF) by a retinal specialist. The classification of DR was assessed in the eye that was the most compromised. Each eye was classified based on whether DR was present. Patients were then classified according to the international classification as: absent, non-proliferative diabetic retinopathy (NPDR), proliferative diabetic retinopathy (PDR) and macular edema [30].

\section{Metabolic syndrome assessment}

The definition of MS was done according to the International Diabetes Federation criteria [31]. Adolescents aged 10 to $<16$ years old were classified according to the following criteria: (1) abdominal obesity: waist circumference (WC) $\geq 90$ th percentile for age and gender; (2) triglycerides $\geq 150 \mathrm{mg} / \mathrm{dL}(1.7 \mathrm{mmol} / \mathrm{L})$; (3) HDL-c $<40 \mathrm{mg} /$ $\mathrm{dL}(1.03 \mathrm{mmol} / \mathrm{L})$; (4) elevated $\mathrm{BP} \geq 130 \times 85 \mathrm{mmHg}$ [22]. As there are no reference values of percentiles on abdominal waist in the Brazilian population, we used the same criterion ( $\geq 90$ th percentile) for each age and gender group of our sample. Considering that all participants had T1D, central obesity plus an additional factor was necessary for diagnosing MS [32]. Adolescents aged 16 years or older were classified according to the same criteria adopted for adults as follows: central obesity: WC $\geq 90 \mathrm{~cm}$ for South American men or $\geq 80 \mathrm{~cm}$ in South American women; triglycerides $\geq 150 \mathrm{mg} / \mathrm{dL}$ $(1.7 \mathrm{mmol} / \mathrm{L})$ or on drug therapy for elevated triglycerides; $\mathrm{HDL}<40 \mathrm{mg} / \mathrm{dL}(1.03 \mathrm{mmol} / \mathrm{L})$ in men or $<50 \mathrm{mg} /$ $\mathrm{dL}(1.29 \mathrm{mmol} / \mathrm{L})$ in women or on drug therapy for low $\mathrm{HDL}$; elevated $\mathrm{BP} \geq 130 \times 85 \mathrm{mmHg}$ or using antihypertensive drugs.

\section{Statistical analysis}

For statistical analysis purpose, normal weight and underweight were grouped together as well as overweight and obesity [33]. An exploratory analysis was initially performed, and the data were presented as mean $( \pm S D)$ or median, interquartile range [IQR] for continuous variables and percentage for discrete variables. Parametric and non-parametric tests were used for comparison between the groups as indicated. Pearson's correlation coefficient was calculated when applicable.

We have done backward Wald logistic multivariate analysis with overweight/obesity as a dependent variable (outcome variable), and for the independent variables, those with $\mathrm{p}<0.2$ in exploratory analysis, or those which presented relevance, mainly related to demographic and social data, such as gender, age, diabetes duration, years of school attendance, self-reported color-race, level of care, family history of hypertension, $\mathrm{sBP}$ and $\mathrm{dBP}$, use of anti-hypertensive drugs, insulin dose $/ \mathrm{kg}$, proportion of basal/bolus insulin doses, geographic region of the country and GFR. Adjustments for social economic status, self-reported color-race and age at diabetes diagnosis 
were performed. All analyses were performed using the Package for the Social Sciences SPSS version 17.0 (SPSS, Inc., Chicago, Illinois, USA). Odds ratios with $95 \%$ confidence intervals (CIs) were calculated where indicated. A two-sided $p$ value less than 0.05 was considered to be significant.

\section{Results}

\section{Overview of the sociodemographic data of the studied population}

Overall, 251 patients (68.4\%) had normal weight, 21 (5.7\%) were underweight and 95 (25.9\%) presented overweight/obesity, with 79 patients (21.5\%) presenting overweight and $16(4.4 \%)$ obesity (Fig. 1$)$. The sociodemographic data of the studied population are listed in Table 1.

\section{Overview of the studied population according to the presence of overweight/obesity}

Clinical, demographic and laboratory data stratified according to the presence of overweight/obesity are described in Table 2. Overall, patients with overweight/ obesity were female, older, had longer diabetes duration, had more frequently acanthosis nigricans, were attended at a tertiary care level center and used lower insulin doses (U/kg/day) but higher total daily insulin dose (U/ day) than those patients without overweight/obesity. No difference was noted concerning the level of HbA1c in the year of the evaluation as well in the previous year. A strong correlation was noted between the last values of HbA1c in the previous year with HbA1c values measured during the study $(\mathrm{r}=0.74, \mathrm{p}<0.001)$. A weak correlation between HbA1c values measured during the study with the levels of total cholesterol $(\mathrm{r}=0.244, \mathrm{p}<0.001)$, triglycerides $(r=0.265, p<0.001)$, ALT $(r=0.143, p=0.007)$

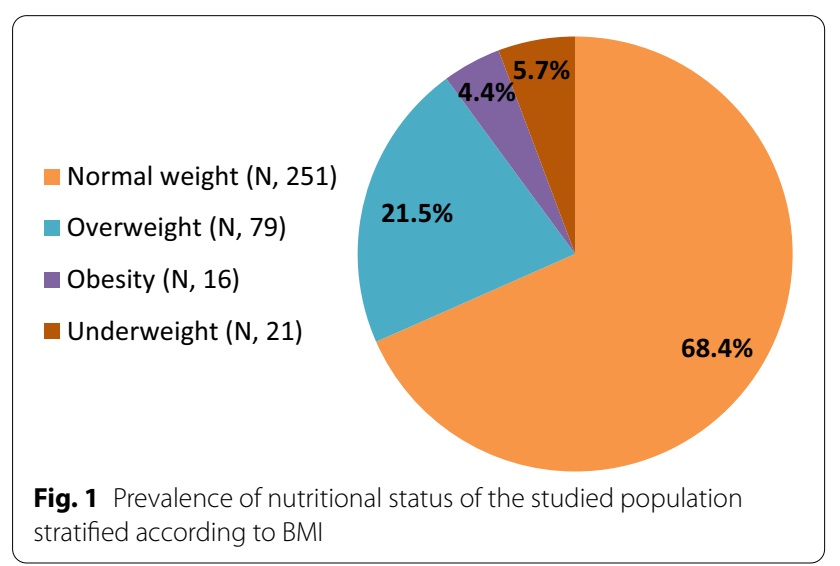

Table 1 Clinical and demographic data of the studied population

\begin{tabular}{ll}
\hline Variable & \\
\hline $\mathrm{N}$ & 367 \\
Age, $y$ & $16.4 \pm 1.9$ \\
Gender, female, $\mathrm{n}(\%)$ & $184(50.1)$ \\
Age at diabetes diagnosis, $\mathrm{y}$ & $8.9 \pm 4.3$ \\
Diabetes duration, $\mathrm{y}$ & $8.1 \pm 4.3$ \\
HbA1c (\%) & $9.6 \pm 2.4$ \\
Ethnicity, $\mathrm{n}(\%)$ & \\
$\quad$ Caucasians & $176(48.0)$ \\
Geographic region, $\mathrm{n}(\%)$ & \\
$\quad$ Southeast & $160(43.6)$ \\
$\quad$ North/northeast & $133(36.2)$ \\
$\quad$ South & $24(6.5)$ \\
$\quad$ Mid-west & $50(13.6)$ \\
Economic status & \\
High & $8(2.2)$ \\
Medium & $151(41.1)$ \\
Low & $193(52.6)$ \\
Very low & $15(4.1)$ \\
Level of care $n(\%)$ & \\
$\quad$ Secondary & $167(45.5)$ \\
Tertiary & $200(54.5)$ \\
Teame of follow-up, $y$ & $5.4 \pm 3.8$ \\
Public exclusively & \\
\hline Public and private & $263(71.7)$ \\
\hline
\end{tabular}

$Y$ year; data are presented as number (percentage), mean $\pm \mathrm{SD}$;

*African-Brazilians, Mulattos, Asians, and Native Indians

and AST $(\mathrm{r}=0.113, \mathrm{p}<0.035)$ was noted. No correlation was found with LDL-C and HDL-C values.

The presence of hypertension, family history of hypertension in first degree relatives and MS were higher in patients with overweight/obesityin comparison to patients without this condition. These patients also had higher levels of total and LDL-cholesterol, high frequency of undesirable levels of LDL-Cholesterol, lower level of GFR and were more frequently under the use of metformin, statins and anti-hypertensive drugs. No difference was observed in the levels of ALT, AST, GGT, uric acid, HDL-cholesterol and triglycerides. A similar prevalence of retinopathy and CKD was observed in patients with and without overweight/obesity. Data described in Table 2

\section{Multivariate logistic analysis with the presence} of overweight/obesity as dependent variable

Multivariate analysis performed with the presence of overweight/obesity as a dependent variable, showed that 
Table 2 Clinical, demographic and laboratory data stratified by the presence of overweight/obesity

\begin{tabular}{|c|c|c|c|}
\hline & \multicolumn{3}{|c|}{ Overweight/obesity } \\
\hline & No & Yes & ${ }^{*} p$-value \\
\hline N (\%) & $272(74.1)$ & $95(25.9)$ & \\
\hline \multicolumn{4}{|l|}{ Demographic data } \\
\hline Gender, female n (\%) & $127(46.7)$ & $57(60.0)$ & 0.03 \\
\hline Age, y & $16.3 \pm 1.9$ & $16.9 \pm 1.8$ & 0.005 \\
\hline Diabetes duration, y & $7.8 \pm 4.2$ & $8.9 \pm 4.4$ & 0.04 \\
\hline Age at diagnosis, y & $8.8 \pm 3.9$ & $8.3 \pm 4.2$ & 0.3 \\
\hline Time of follow up, y & $5.0[6.0]$ & $5.0[5.7]$ & 0.7 \\
\hline Level of care, tertiary n (\%) & 137(50.4) & 63(66.3) & 0.008 \\
\hline Health insurance(public and private), yes n(\%) & $80(29.4)$ & $24(25.3)$ & 0.5 \\
\hline Years of study, y & $10.9 \pm 2.5$ & $10.8 \pm 2.3$ & 0.8 \\
\hline Smoker, yes n(\%) & $9(3.3)$ & $8(8.4)$ & 0.05 \\
\hline \multicolumn{4}{|l|}{ Ethnicity, y (\%)† } \\
\hline Caucasians & $127(46.7)$ & $49(51.6)$ & 0.4 \\
\hline Geographic region, n (\%) & & & $<0.001$ \\
\hline Southeast & $98(36.0)$ & $56(58.9)$ & \\
\hline South & $17(6.3)$ & $6(6.3)$ & \\
\hline North/Northeast & 106(39.0) & $28(29.5)$ & \\
\hline Mid-west & $51(10.9)$ & $5(5.3)$ & \\
\hline Economic status (\%) & & & 0.5 \\
\hline High & $7(2.6)$ & $1(1.1)$ & \\
\hline Medium & $111(40.8)$ & $40(42.1)$ & \\
\hline Low & $141(51.8)$ & $52(54.7)$ & \\
\hline Very low & $13(4.8)$ & $2(2.1)$ & \\
\hline \multicolumn{4}{|l|}{ Diabetes management and treatment } \\
\hline $\mathrm{HbA1c}(\%)$ & $9.7 \pm 2.5$ & $9.5 \pm 2.3$ & 0.6 \\
\hline $\mathrm{HbA} 1 \mathrm{c}(\mathrm{mmol} / \mathrm{mol})$ & $82.4 \pm 26.9$ & $80.9 \pm 25.7$ & \\
\hline $\mathrm{HbA} 1 \mathrm{c}<7.5 \% \mathrm{n}(\%)$ & $48(17.7)$ & $16(16.8)$ & 0.6 \\
\hline $\begin{array}{l}\mathrm{HbA1c}(\%) \text { year before } \\
\mathrm{HbA1c}(\mathrm{mmol} / \mathrm{mol}) \text {, year before }\end{array}$ & $\begin{array}{l}9.8 \pm 2.7 \\
84.4 \pm 29.8\end{array}$ & $\begin{array}{l}9.5 \pm 2.7 \\
80.7 \pm 29.7\end{array}$ & 0.3 \\
\hline Insulin dose (U/kg/day) & $1.05 \pm 0.4$ & $0.95 \pm 0.4$ & 0.04 \\
\hline Insulin dose, total (U/day) & $58.26 \pm 21.2$ & $65.67 \pm 25.2$ & 0.01 \\
\hline SMBG, yes n (\%) & 266(97.8) & $91(95.8)$ & 0.3 \\
\hline SMBG, $\mathrm{n}$ & $3.7 \pm 1.4$ & $3.9 \pm 1.3$ & 0.18 \\
\hline Adherence to diet, yes n(\%) & $124(51.0)$ & $37(44.6)$ & 0.3 \\
\hline Physical activity, yes $n(\%)^{\dagger+}$ & $175(64.3)$ & $61(64.2)$ & 0.9 \\
\hline Number of clinical visits/year & $3.8 \pm 1.7$ & $3.7 \pm 1.7$ & 0.95 \\
\hline Diabetes treatment, $\mathrm{n}(\%)^{* *}$ & & & 0.9 \\
\hline $\mathrm{NPH}$ or $\mathrm{NPH}+$ regular & $255(93.8)$ & $90(94.7)$ & \\
\hline Insulin analogs (long or short acting) or CSII & $17(6.2)$ & $5(5.2)$ & \\
\hline Adherence to ITR, yes n(\%) & 23(13.7) & $8(13.6)$ & 0.9 \\
\hline \multicolumn{4}{|l|}{ Clinical data } \\
\hline $\mathrm{BMI}, \mathrm{kg} / \mathrm{m}^{2}$ & $20,6 \pm 2.2$ & $26,7 \pm 2.5$ & $<0.001$ \\
\hline Waist circumference, $\mathrm{cm}$ & $73.6 \pm 6.8$ & $87.5 \pm 8.5$ & $<0.001$ \\
\hline Systolic blood pressure & $111.4 \pm 11.4$ & $118.0 \pm 10.3$ & $<0.001$ \\
\hline Diastolic blood pressure & $68.5 \pm 9.0$ & $73.9 \pm 8.4$ & $<0.001$ \\
\hline Hypertension, yes n(\%) & $28(10.3)$ & $19(20.2)$ & $<0.001$ \\
\hline Acanthosis yes n(\%) & $3(1.1)$ & $8(8.4)$ & $<0.001$ \\
\hline Metabolic syndrome, yes n(\%) & $8(2.9)$ & $30(31.9)$ & $<0.001$ \\
\hline
\end{tabular}


Table 2 (continued)

\begin{tabular}{|c|c|c|c|}
\hline & \multicolumn{3}{|c|}{ Overweight/obesity } \\
\hline & No & Yes & ${ }^{*} p$-value \\
\hline \multicolumn{4}{|l|}{ Laboratorial data } \\
\hline Uric acid (mg/dL) & $4.8 \pm 1.4$ & $4.8 \pm 1.6$ & 0.6 \\
\hline Total Cholesterol (mg/dL) & $182.4 \pm 55.2$ & $197.1 \pm 57.2$ & 0.03 \\
\hline Triglycerides (mg/dL) & $85[58.0]$ & $80.5[65.7]$ & 0.2 \\
\hline High triglycerides, yes n(\%) & $40(15.2)$ & $12(13)$ & 0.7 \\
\hline HDL-cholesterol (mg/dL) & $54.4 \pm 15.4$ & $55.7 \pm 18.9$ & 0.7 \\
\hline Low HDL-Cholesterol, yes n(\%) & $62(23.6)$ & $26(28.3)$ & 0.4 \\
\hline LDL-cholesterol (mg/dL) & $106.3 \pm 41.8$ & $120.2 \pm 39.4$ & 0.006 \\
\hline LDL-cholesterol $\geq 100$ mg/dl,n(\%) & $128(48.5)$ & $57(64)$ & 0.014 \\
\hline Non-HDL-cholesterol(mg/dL) & $127.9 \pm 50.9$ & $141.3 \pm 51.3$ & 0.03 \\
\hline$A L T, U / L$ & $13[8.0]$ & $11[10.0]$ & 0.45 \\
\hline AST, U/L & $16[11]$ & $16[12.5]$ & 0.4 \\
\hline $\mathrm{GGT}, \mathrm{mg} / \mathrm{dL}$ & $16[10]$ & $18[12]$ & 0.1 \\
\hline \multicolumn{4}{|l|}{ Medications } \\
\hline Metformin, yes n(\%) & $10(3.7)$ & $25(26.3)$ & $<0.001$ \\
\hline Anti-hypertensive drugs, yes n(\%) & $17(6.3)$ & 15(16.0) & 0.004 \\
\hline Statins yes $\mathrm{n}(\%)$ & $10(3.7)$ & $9(9.5)$ & 0.03 \\
\hline \multicolumn{4}{|l|}{ Family history } \\
\hline Overweight/obesity, yes n(\%) & $60(22.1)$ & $20(21.1)$ & 0.8 \\
\hline Type 2 diabetes, yes n(\%) & $30(11.0)$ & 13(13.7) & 0.4 \\
\hline Hypertension & 98(36.6) & 49(53.3) & 0.007 \\
\hline Coronary disease & 13(4.9) & $6(6.5)$ & 0.5 \\
\hline \multicolumn{4}{|l|}{ Diabetes-related chronic complications } \\
\hline Retinopathy, yes n (\%) & 19(7.1) & $9(9.7)$ & 0.5 \\
\hline CKD, yes n (\%) & $33(16.8)$ & $13(16.7)$ & 0.9 \\
\hline $\mathrm{GFR}, \mathrm{mL} / \mathrm{min} / 1.73 \mathrm{~m}^{2} * * *$ & $115.9 \pm 32.6$ & $106.8 \pm 23.4$ & 0.01 \\
\hline Albuminuria, mg/dL & $8.8[13.11]$ & $7.5[16.76]$ & 0.4 \\
\hline
\end{tabular}

The data are presented as $\mathrm{n}(\%)$, mean $\pm \mathrm{SD}$ or median [IQR, interquartile range];

†African-Brazilians, Mulattos, Asians, Native Amerindians were considered as non-Caucasians; ${ }^{*} \mathrm{p}<0.05$ was considered significant. ${ }^{* *}$ For this analysis we considered patients using exclusively insulin provided by the government, free of charge (NPH or Regular) and those using only insulin analogs (long/short acting or CSII), CSII continuous subcutaneous insulin infusion, ITR insulin therapeutic regimens, ${ }^{\dagger+}$ Physical activity, at least $3 /$ times per week. ALT alanine aminotransferase, AST aspartate aminotransferase, GGT gamma-glutamyl transferase, ${ }^{* * *}$ glomerular filtration rate

all the independent variables which entered in the model, could explain 20.7\% (Nagelkerke R-squared) of a given patient having overweight/obesity. $73.8 \%$ of the patients were correctly classified by the model. The presence of overweight/obesity was associated with female gender, age, sBP, and showed a tendency to be associated with geographic region of the country and with the use of anti-hypertensive drugs. Data described in Table 3.

\section{Discussion}

Our study has shown that almost one quarter of our adolescents with T1D, presented overweight/obesity. Having overweight/obesity was associated with some traditional risk factors for DRCC and CVD such as diabetes duration, hypertension, LDL-cholesterol and MS. The above-mentioned data pointed out that these patients aggregated factors associated with micro and macrovascular DRCC which could translate into poor clinical prognosis in the future [34-36]. Although no association was found with glycemic control (current and in the previous year) it is important to emphasize that less than $20 \%$ of the patients in both groups presented an adequate glycemic control. No association was found between overweight/obesity with diabetic CKD, retinopathy and laboratorial markers of NAFLD.

The prevalence of overweight/obesity in patients with T1D ranged from 12 to $38.5 \%$ in studies conducted in different countries [2, 14, 37-40]. Our study showed a prevalence of overweight/obesity of about $25 \%$ that was within the above-mentioned range for T1D, with 
Table 3 Final model of logistic regression with overweight/obesity as dependent variable

\begin{tabular}{lllll}
\hline Variable & B & OR & 95\% confidence interval & p value \\
\hline Age, years & 0.158 & 0.171 & $1.000-1.143$ & 0.05 \\
Gender, female & 0.944 & 2.570 & $1.454-4.542$ & 0.01 \\
SBP & 0.043 & 1.044 & $1.010-1.080$ & $<0.001$ \\
Use of anti-hypertensive drugs & -0.743 & 0.476 & $0.214-1.054$ & 0.06 \\
Geographic regions & & & & 0.05 \\
Mid-West & & 1 & $1.362-12.807$ & Reference \\
Southeast & 1.429 & 4.176 & $0.026-2.342$ & 0.01 \\
South & 0.917 & 2.502 & $0.849-8.278$ & 0.213 \\
Northeast/North & 0.975 & 2.651 & 0.09 \\
\hline
\end{tabular}

Adjusted for age at diabetes diagnosis, self-reported color-race and socioeconomic status

$s B P$ systolic blood pressure

no relationship with self-reported color-race and economic status, unlike in the USA, where the prevalence of overweight/obesity was higher among minorities [39]. In multivariate analysis only gender, age, sBP persisted associated with overweight/obesity possibly due to our sample size that was smaller than those evaluated in other studies [13, 37, 38]. Gender, age and sBP have been described as being associated with overweight/obesity in many different studies $[13,14,39]$.

A higher prevalence of MS was noted in patients with overweight/obesity in comparison to patients without this clinical condition. It is noteworthy that these latter patients still have a higher prevalence of MS than adolescents without T1D in Brazil which was $1.6 \%$ when the IDF criteria were used [41]. A relationship between micro and macrovascular complications in patients with T1D with MS and each of its components has been observed $[4,42]$. In our study, hypertension, high sBP and $\mathrm{dBP}$ were some of the most important components of MS observed in patients with T1D and overweight/obesity similar to other studies, in T1D [36] and in individuals without T1D [41]. Nevertheless, no association between overweight/obesity with diabetic CKD and retinopathy was observed in the present study. The presence of hypertension, high sBP in the life-course of these patients is a risk factor for the development of these microvascular complications as has been previously demonstrated $[43,44]$. Another factor that could also be a background risk factor for the above-mentioned conditions was the family history of hypertension that was higher in the group of patients with overweight/obesity. No difference in the average value of HDL-cholesterol and triglycerides was found in our patients which was not observed in other studies [36, 37]. This could be related to our sample size as well as to demographic characteristics of our population such as lower age and diabetes duration. Similar to other studies performed in patients with T1D, our patients showed a positive correlation between $\mathrm{HbA1c}$ and total cholesterol [43]. Patients with overweight/obesity presented higher levels of total and LDL-cholesterol, which result in a higher risk for CVD [37, 45]. We did not measure obesity-related hormones such as ghrelin which could have added some information regarding the pathogenesis of overweight/obesity in this group of patients. However, the role of this hormone in patients with T1D T1D is still controversial [46].

Our data did not show an association between overweight/obesity with the levels of HbA1c, and with the number of patients that reached the targets for good glycemic control. Controversial results have been described in patients with T1D with overweight/obesity concerning glycemic control [7, 12-14, 37]. A Dutch study showed average higher HbA1c levels in patients with overweight/ obesity but without difference in the number of patients that presented HbA1c levels $<7.5 \%$ [36]. The Finn Dianne study, that included adult patients with MS, showed its association with an inadequate glycemic control [7].

Some studies showed an association between good glycemic control and overweight/obesity probably related to insulin intensive treatment $[11,12]$. This fact was not observed in our study. Although the majority of our patients were under the use of multiple insulin injections, less than $50 \%$ reported adherence to diet, and also less than $20 \%$ reported adherence to IRTs which has an impact upon glycemic control [14, 17]. However, studies that have focused on the levels of HbA1c in patients with T1D, with and without overweight/obesity, have found a difference in HbA1c levels no greater than $0.5 \%$.

An interesting point observed in the present study was the use of lower insulin doses $(\mathrm{U} / \mathrm{kg} /$ day) but higher total insulin dose (U/day) in patients with overweight/obesity. This probably occurred because these patients had higher body surface which could be related to insulin resistance that is usually found among these patients [3, 4]. 
However, it is important to emphasize that the majority of the studies present their data taking in account insulin dosage as $\mathrm{U} / \mathrm{Kg} /$ day, and the results regarding the presence of overweight/obesity is still controversial $[4,33]$

Finally, the use of metformin had a negative effect on overweight/obesity. It was used as adjunct therapy to insulin by $26.3 \%$ of our patients with overweight/obesity, mainly females (data not shown). Although these patients had similar levels of HbA1c, they used lower insulin doses than those with normal weight. Other studies that have also evaluated metformin in overweight/obese patients with T1D showed that metformin use was associated with significant reductions in HbA1c levels and insulin doses, with no significant changes in weight [47]. Another study, conducted in Denmark, using metformin or placebo as adjunct to insulin did not find a significant difference on HbA1c levels, but the insulin doses and weight showed significant reductions [48]. As expected, patients with overweight/obesity were more frequently using anti-hypertensive drugs and statins.

Our data were obtained and evaluated very uniformly and had a broad spectrum, which led us to evaluate many covariates, which was, consequently, a strength of our study.

Some limitations of our study must also be mentioned. Firstly, similar to other epidemiologic studies conducted with T1D $[13,33]$, we did not measure $C$ peptide levels, nor autoantibodies against beta cells, and used only clinical criteria for T1D diagnosis. Secondly, all the information about adherence to diet and to ITRs as well as practice of regular physical activity were self-reported. Thirdly, as we did not have the weight of the patients at the moment the diagnosis was made, we could not know if the presence of overweight/obesity was already present since then. Finally, as our study had a cross-sectional design, a causal relationship between those factors found to be associated with overweight/obesity and the presence of this clinical condition cannot be established.

\section{Conclusions}

Almost one quarter of our patients presented overweight/obesity. These patients had higher prevalence of traditional risk factors for micro and macrovascular DRCC such as diabetes duration, hypertension, high levels of LDL-cholesterol and presence of MS. The majority of patients with or without overweight/ obesity presented inadequate glycemic control that is also an important risk factor for these complications. No association was found between overweight/obesity with diabetic CKD, DR and laboratorial markers of NAFLD. The above-mentioned data point out that further prospective studies are urgently needed to establish the clinical prognosis of these young patients.

\section{Abbreviations}

T1D:Type 1 diabetes; MS: Metabolic syndrome; DCCT: The Diabetes Control and Complications Trial; EDIC: The Epidemiology of Diabetes Interventions and Complications; BMI: Body mass index; $\mathrm{HbA}_{1} \mathrm{C}$ : Glycated hemoglobin; $\mathrm{NPH}$ : Neutral protamine Hagedorn; BNHCS: Brazilian National Health Care System; SMBG: Self-monitoring of blood glucose; ITR: Insulin therapeutic regimen; HPLC: High-performance liquid chromatography; ALT: Alanine aminotransferase; AST: Aspartate aminotransferase; CSII: Continuous subcutaneous insulin infusion; sBP: Systolic blood pressure; dBP: Diastolic blood pressure; IBGE: Brazilian Institute of Geography and Statistics; CKD: Chronic kidney disease; eGFR: Estimated glomerular filtration rate; DR: Diabetic retinopathy; NPDR: Non-proliferative diabetic retinopathy; PDR: Proliferative diabetic retinopathy (PDR); WC: Waist circumference; DRCC: Diabetes-related chronic complications; CVD: Cardiovascular diseases.

\section{Acknowledgements}

We thank Mrs. Elisangela Santos, Maria Fátima Bevilacqua, Eliete Leão and Vitor Alves Branco, from the State University of Rio de Janeiro, for their technical assistance.

We also acknowledge the participants of Brazilian Type 1 Diabetes Study Group as follows:

Executive steering committee: Marilia Brito Gomes (chair), Carlos Antonio Negrato.

Principal investigators of each center are indicated by an asterisk.

Department of Internal Medicine, Diabetes Unit, State University of Rio de Janeiro, Brazil: Marilia Brito Gomes* (mariliabgomes@gmail.com).

Department of Internal Medicine, Diabetes Unit, State University of Rio de Janeiro, Brazil: Roberta Cobas (robertacobas@gmail.com) Lucianne Righeti MonteiroTannus (luciannetannus@ig.com.br).

Federal University Hospital of Rio de Janeiro: Melanie Rodacki*, M.D. (mrodacki2001@yahoo.com.br); Lenita Zajdenverg, M.D. (lenitazaj@gmail.com) Joana Rodrigues Dantas, M.D. (joanardantasp@ig.com.br).

Diabetes Unit, University Hospital of São Paulo, São Paulo: Maria Lúcia Cardillo Corrêa-Giannella*, M.D. (malugia@lim25fm.usp.br); Sharon Nina Admoni, M.D. (sharonadmoni@gmail.com); Daniele Pereira dos Santos, M.D. (dps.daniele@ hotmail.com).

Bauru's Diabetics Association, Bauru, São Paulo: Carlos Antonio Negrato*, M.D. (carlosnegrato@uol.com.br); Maria de Fatima Guedes, M.D. (tatiguedeses@ hotmail.com).

Diabetes Unit, Federal University of São Paulo State, São Paulo: Sergio Atala Dib*, M.D. (sergio.dib@unifesp.br); Celso Ferreira de Camargo Sallum Filho, M.D. (celsosallum@superig.com.br).

Diabetes Unit, University of Campinas, São Paulo: Elisabeth João Pavin*, M.D. (ejpavin@fcm.unicamp.br); Caroline Takano, M.D. (caroline.takano@gmail.com). Clinical Hospital of the Federal University of Paraná: Rosângela Roginski Rea*, M.D. (rosangelarea@uol.com.br); Nicole Balster Romanzini, M.D. (nikbr@ hotmail.com).

Clinical Hospital of Porto Alegre, Rio Grande do Sul: Mirela Azevedo*, M.D. (mirelajobimazevedo@gmail.com); Luis Henrique Canani, M.D. (luishenriquecanani@gmail.com).

Regional Hospital of Taguatinga, Brasília: Hermelinda Cordeiro Pedrosa*, M.D. (pedrosa.hc@globo.com); Monica Tolentino (monicatolentino@uol.com.br); Cejana Hamu Aguiar, M.D.

Diabetes and Endocrinology Center of Bahia: Reine Marie Chaves Fonseca*, M.D. (reinemar@terra.com.br); Ludmila Chaves Fonseca M.D., Raffaele Kasprowicz, M.D. (raffaellebarros@hotmail.com).

Diabetes and Hypertension Center of Ceará : Adriana Costa e Forti , M.D. (adrianaforti@uol.com.br); Angela Delmira Nunes Mendes, M.D. (angeladelmira@ terra.com.br).

Federal University of Ceará: Renan Montenegro Junior*, M. D. (renanjr@ufc.br); Virgínia Oliveira Fernandes, M.D. (virginiafernande@hotmail.com).

Federal University Hospital of Pará: João Soares Felício*, M. D. (felicio.bel@terra. com.br); Flavia Marques Santos, M.D. (drafms@bol.com.br). 


\section{Authors' contributions}

MBG and CAN analyzed the data and wrote the manuscript. DC, KRGD, FM AAP, FSLL and PHM structured the database and evaluated retinopathy. All authors corrected the final version.

\section{Funding}

This work was supported by grants from Fundação do Amparo à Pesquisa do Estado do Rio de Janeiro and Conselho Nacional de Desenvolvimento Científico e Tecnológico do Brasil.

\section{Availability of data and materials}

The datasets used and/or analyzed during the current study are available from the first author on reasonable request.

\section{Declarations}

\section{Ethics approval and consent to participate}

This study was conducted according to the guidelines of the Declaration of Helsinki, and approved by the Ethics Committee of Hospital Universitário Pedro Ernesto, (protocol code 2769/2010; November 10 ${ }^{\text {th }} 2010$ ).

\section{Consent for publication}

$$
\text { Not applicable. }
$$

\section{Competing interests}

The authors declare that they have no competing interests.

\section{Author details}

${ }^{1}$ Department of Internal Medicine, Diabetes Unit, State University of Rio de Janeiro, Rio de Janeiro, Brazil. ${ }^{2}$ Department of Ophthalmology, Federal University of São Paulo, São Paulo, Brazil. ${ }^{3}$ Department of Ophthalmology, Federal University of Rio Grande Do Sul (UFRGS), Rio Grande do Sul, Brazil. ${ }^{4}$ Department of Ophthalmology, Regional Hospital of Taguatinga, Brasília, Brazil. ${ }^{5}$ Department of Ophthalmology, University of Campinas, Campinas, São Paulo, Brazil. ${ }^{6}$ Medical Doctor Program, University of São Paulo- School of Dentistry, Rua Saint Martin 27-07, Bauru, São Paulo Zip Code: 17012433, Brazil.

Received: 19 September 2021 Accepted: 15 November 2021 Published online: 04 January 2022

\section{References}

1. Pozzilli P, Guglielmi C, Caprio S, Buzzetti R. Obesity, autoimmunity, and double diabetes in youth. Diabetes Care. 2011;34(Suppl2):S166-70. https://doi.org/10.2337/dc11-s213.

2. Libman IM, Pietropaolo M, Arslanian SA, LaPorte RE, Becker DJ. Changing prevalence of overweight children and adolescents at onset of insulintreated diabetes. Diabetes Care. 2003;26(10):2871-5. https://doi.org/10. 2337/diacare.26.10.2871.

3. Cleland SJ, Fisher BM, Colhoun HM, Sattar N, Petrie JR. Insulin resistance in type 1 diabetes: what is "double diabetes" and what are the risks? Diabetologia. 2013:56(7):1462-70. https://doi.org/10.1007/s00125-013-2904-2.

4. Giuffrida FM, Bulcão C, Cobas RA, Negrato CA, Gomes MB, Dib SA. Brazilian Type 1 Diabetes Study Group (BrazDiab1SG). Double-diabetes in a real-world sample of 2711 individuals: associated with insulin treatment or part of the heterogeneity of type 1 diabetes? Diabetol Metab Syndr. 2016;22(8):28. https://doi.org/10.1186/s13098-016-0143-7 (eCollection 2016).

5. Teupe B, Bergis K. Epidemiological evidence for "double diabetes." Lancet. 1991:337(8737):361-2. https://doi.org/10.1016/0140-6736(91)90988-2.

6. Purnell JQ, Hokanson JE, Marcovina SM, Steffes MW, Cleary PA, Brunzell $J D$. Effect of excessive weight gain with intensive therapy of type 1 diabetes on lipid levels and blood pressure: results from the DCCT Diabetes Control and Complications Trial. JAMA. 1998;280(2):140-6. https://doi. org/10.1001/jama.280.2.140.

7. Thorn LM, Forsblom C, Wadén J, Saraheimo M, Tolonen N, Hietala K, Groop PH. Finnish Diabetic Nephropathy (FinnDiane) Study Group Metabolic syndrome as a risk factor for cardiovascular disease, mortality, and progression of diabetic nephropathy in type 1 diabetes.
Diabetes Care. 2009;32:950-2. https://doi.org/10.2337/dc08-2022 (Epub 2009 Feb 5).

8. Barros BSV, Monteiro FC, Terra C, Gomes MB. Prevalence of nonalcoholic fatty liver disease and its associated factors in individuals with type 1 diabetes: a cross-sectional study in a tertiary care center in Brazil. Diabetol Metab Syndr. 2021;13(1):33. https://doi.org/10.1186/ s13098-021-00649-0.

9. Belete R, Ataro Z, Abdu A, Sheleme M. Global prevalence of metabolic Syndrome among patients with type I diabetes mellitus: a systematic review and meta-analysis. Diabetol Metab Syndr. 2021;13(1):25. https:// doi.org/10.1186/s13098-021-00641-8.

10. Chaturvedi N, Sjoelie AK, Porta M, Aldington SJ, Fuller JH, Songini M, Kohner EM. Markers of insulin resistance are strong risk factors for retinopathy incidence in type 1 diabetes EURODIAB Prospective Complications Study. Diabetes Care. 2001;24:284-9. https://doi.org/10.2337/diacare.24.2.284.

11. The DCCT Research Group. Weight gain associated with intensive therapy in the diabetes control and complications trial. Diabetes Care. 1998;11(7):567-73. https://doi.org/10.2337/diacare.11.7.567.

12. Fröhlich-Reiterer EE, Rosenbauer J, Bechtold-Dalla Pozza S, Hofer SE, Schober E, Holl RW, et al. Predictors of increasing BMI during the course of diabetes in children and adolescents with type 1 diabetes: data from the German/Austrian DPV multicentre survey. Arch Dis Child. 2014;99(8):738-43. https://doi.org/10.1136/archdischild-2013-304237.

13. Minges KE, Whittemore R, Weinzimer SA, Irwin ML, Redeker NS, Grey M. Correlates of overweight and obesity in 5529 adolescents with type 1 diabetes: The T1D Exchange Clinic Registry. Diabetes Res Clin Pract. 2017;126:68-78. https://doi.org/10.1016/j.diabres.2017.01.012.

14. Gomes MB, Negrato CA. Adherence to insulin therapeutic regimens in patients with type 1 diabetes. A nationwide survey in Brazil. Diabetes Res Clin Pract. 2016;120:47-55. https://doi.org/10.1016/j.diabres.2016.07.011.

15. World Health Organization. Maternal, newborn, child and adolescent health/topics at a glance/adolescent health/Health for the world's adolescents. (www.who.int; apps.who.int). Accessed in September 2019.

16. IBGE Censo 2010. [Acessed in January,12,2020]. http://www.censo2010. ibge.gov.br.

17. Davison KA, Negrato CA, Cobas R, Matheus A, Tannus L, Palma CS et al. Brazilian Type 1 Diabetes Study Group (BrazDiab1SG). Relationship between adherence to diet, glycemic control and cardiovascular risk factors in patients with type 1 diabetes: a nationwide survey in Brazil. Nutr J.2014; 13:19. doi: https://doi.org/10.1186/1475-2891-13-19

18. American Diabetes Association. Clinical practice recommendations. Diabetes Care. 2021;44:S180-199.

19. Friedwald WT, Levy RI, Fredrickson DS. Estimations of serum low density lipoprotein cholesterol without use of preparative ultracentrifuge. Clin Chem. 1972;18(6):499-502 (PMID: 4337382).

20. World Health Organization. Obesity: preventing and managing the global epidemic. Report of a World Health Organization Consultation. Geneva: World Health Organization, 2000. p256. WHO Obesity Technical Report Series, n.284. PMID: 11234459

21. Flynn JT, Kaelber DC, Baker-Smith CM, Blowey D, Carroll AE, Daniels SR, et al. Clinical practice guideline for screening and management of high blood pressure in children and adolescents. Pediatrics. 2017;140(3): e20171904. https://doi.org/10.1542/peds.2017-1904.

22. Gomes MB, de Mattos Matheus AS, Calliari LE, Luescher JL, Manna TD, Savoldelli RD, et al. Economic status and clinical care in young type 1 diabetes patients: a nationwide multicenter study in Brazil. Acta Diabetol. 2013;50(5):743-52. https://doi.org/10.1007/s00592-012-0404-3.

23. Instituto Brasileiro de Geografia e Estatística (IBGE). Censo 2000 [accessed in 2008 Aug.]. http:/www.ibge.gov.br/censo

24. Malerbi DA, Franco LJ. Multicenter study of the prevalence of diabetes mellitus and impaired glucose tolerance in the urban Brazilian population aged 30-69 yr. The Brazilian Cooperative Group on the Study of Diabetes Prevalence. Diabetes Care. 1992;15(11):1509-16. https://doi.org/ 10.2337/diacare.15.11.1509.

25. ABEP. Brazilian Economic classification criteria, 2010 [accessed in 2008 aug]. http://www.abep.org/novo/Content.aspx?SectionID=84

26. Levey AS, Stevens LA, Schmid CH, Zhang YL, Castro AF 3rd, Feldman HI, et al. A new equation to estimate glomerular filtration rate. Ann Intern Med. 2009;150(9):604-12. https://doi.org/10.7326/0003-4819-150-9200905050-00006. 
27. Schwartz GJ, Work DF. Measurement and estimation of GFR in children and adolescents. Clin J Am Soc Nephrol. 2009;4(11):1832-43. https://doi. org/10.2215/CJN.01640309.

28. Webster AC, Nagler EV, Morton RL, Masson P. Chronic kidney disease. Lancet. 2017;389(10075):1238-52. https://doi.org/10.1016/S0140-6736(16) 32064-5.

29. Kidney Disease: Improving Global Outcomes (KDIGO) CKD Work Group. KDIGO 2012 Clinical practice guideline for the evaluation and management of chronic kidney disease. In. Kidney.2013: Int Suppl 1-150.

30. Wilkinson CP, Ferris FL 3rd, Klein RE, Lee PP, Agardh CD, Davis M, et al. Proposed international clinical diabetic retinopathy and diabetic macular edema disease severity scales. Ophthalmology. 2003;110(9):1677-82. https://doi.org/10.1016/S0161-6420(03)00475-5.

31. Alberti KGMM, Zimmet P, Shaw J, George K, Alberti MM, Aschner P, et al. Metabolic syndrome-a new world-wide definition. A Consensus Statement from the International Diabetes Federation. Diabetic Med. 2006;23(5):469-80. https://doi.org/10.1111/j.1464-5491.2006.01858.x.

32. IDF consensus definition of metabolic syndrome in children and adolescents .https://www.idf.org/, Accessed Jan 2020.

33. Bell RA, Mayer-Davis EJ, Beyer JW, D'Agostino RB Jr, Lawrence JM, Linder B, Liu LL, Marcovina SM, Rodriguez BL, Williams D, Dabelea D, SEARCH for Diabetes in Youth Study Group. Diabetes in non-Hispanic white youth: prevalence, incidence, and clinical characteristics: the SEARCH for Diabetes in Youth Study. Diabetes Care. 2009;32(Suppl 2):S102-11. https://doi. org/10.2337/dc09-S202.

34. Sistema de Vigilância Nutricional e Alimentar. Available from https:// sisaps.saude.gov.br/sisvan/relatoriopublico/index. Acessed Feb 2021

35. NCD Risk Factor Collaboration (NCD-RisC). Worldwide trends in bodymass index, underweight, overweight, and obesity from 1975 to 2016: a pooled analysis of 2416 population-based measurement studies in 128.9 million children, adolescents, and adults. Lancet. 2017;390(10113):262742. https://doi.org/10.1016/S0140-6736(17)32129-3.

36. van Vliet $M$, Van der Heyden JC, Diamant $M$, Von Rosenstiel IA, Schindhelm RK, Aanstoot HJ, et al. Overweight is highly prevalent in children with type 1 diabetes and associates with cardiometabolic risk. J Pediatr. 2010;156(6):923-9. https://doi.org/10.1016/j.jpeds.2009.12.017.

37. Schwab KO, Doerfer J, Marg W, Schober E, Holl RW, DPV Science Initiative and the Competence Network Diabetes mellitus. Characterization of 33488 children and adolescents with type 1 diabetes based on the gender-specific increase of cardiovascular risk factors. Pediatr Diabetes. 2010;11(5):357-63. https://doi.org/10.1111/j.1399-5448.2010.00665.x.

38. Flechtner-Mors M, Schwab KO, Fröhlich-Reiterer EE, Kapellen TM, Meissner T, Rosenbauer J, et al. Overweight and obesity based on four reference systems in 18,382 paediatric patients with type 1 diabetes from Germany and Austria. J Diabetes Res. 2015;2015: 370753. https://doi.org/ $10.1155 / 2015 / 370753$.

39. Liu LL, Lawrence JM, Davis C, Liese AD, Pettitt DJ, Pihoker C, et al. Prevalence of overweight and obesity in youth with diabetes in USA: the SEARCH for Diabetes in Youth study. Pediatr Diabetes. 2010;11(1):4-11. https://doi.org/10.1111/j.1399-5448.2009.00519.x.

40. Gomes MB, Gabrielli AB, Santos DC, Pizarro MH, Barros BSV, Negrato CA, et al. Self-reported color-race and genomic ancestry in an admixed population: a contribution of a nationwide survey in patients with type 1 diabetes in Brazil. Diabetes Res Clin Pract. 2018;140:245-52. https://doi. org/10.1016/j.diabres.2018.03.021 (Epub 2018 Mar 21).

41. Alvarez MM, Vieira ACRE, Sichieri R, da Veiga GV. Prevalence of metabolic syndrome and of its specific components among adolescents from Niterói City, Rio de Janeiro State. Brazil Arq Bras Endocrinol Metabol. 2011;55(2):164-70. https://doi.org/10.1590/S0004-27302011000200009.

42. Davis TME, Bruce DG, Davis WA. Prevalence and prognostic implications of the metabolic syndrome in community-based patients with type 1 diabetes: The Fremantle Diabetes Study. Diabetes Res Clin Pract. 2007;78(3):412-7. https://doi.org/10.1016/j.diabres.2007.06.007.

43. de Melo LGN, Morales PH, Drummond KRG, Santos DC, Haas Pizarro M, Barros BSV, et al. Prevalence and risk factors for referable diabetic retinopathy in patients with type 1 diabetes: a nationwide study in Brazil. Acta Ophthalmol. 2018;96(8):e1032-3. https://doi.org/10.1111/aos.13760.

44. Gomes MB, Pizarro MH, Muniz LH, Barros BSV, Melo LGN, Santos DC, et al. Prevalence of chronic kidney disease in an admixed population of patients with type 1 diabetes. A multicenter study in Brazil. Diabetes
Res Clin Pract. 2020;170:108490. https://doi.org/10.1016/j.diabres.2020. 108490.

45. Petitti DB, Imperatore G, Pall AL, Daniels SR, Dollan LM, Kershnar AK, Marcovina S, et al. Serum lipids and glucose control. Arch Pediatr Adolesc Med. 2007;161(2):159-65. https://doi.org/10.1001/archpedi.161.2.159.

46. Özcan B, Delhanty PJD, Huisman M, Visser JA, Neggers SJ, van der Lely AJ. Overweight and obesity in type 1 diabetes is not associated with higher ghrelin concentrations. Diabetol Metab Syndr. 2021;13(1):79. https://doi. org/10.1186/s13098-021-00699-4.

47. Khan AS, McLoughney CR, Ahmed AB. The effect of metformin on blood glucose control in overweight patients with type 1 diabetes. Diabet Med. 2006;23(10):1079-84. https://doi.org/10.1111/j.1464-5491.2006.01966.x.

48. Jacobsen IB, Henriksen JE, Beck-Nielsen $\mathrm{H}$. The effect of metformin in overweight patients with type 1 diabetes and poor metabolic control. Basic Clin Pharmacol Toxicol. 2009;105(3):145-9. https://doi.org/10.1111/j. 1742-7843.2009.00380.x.

\section{Publisher's Note}

Springer Nature remains neutral with regard to jurisdictional claims in published maps and institutional affiliations.

Ready to submit your research? Choose BMC and benefit from:

- fast, convenient online submission

- thorough peer review by experienced researchers in your field

- rapid publication on acceptance

- support for research data, including large and complex data types

- gold Open Access which fosters wider collaboration and increased citations

- maximum visibility for your research: over 100M website views per year

At BMC, research is always in progress.

Learn more biomedcentral.com/submissions 